\title{
O descompasso da Lei de Responsabilidade Fiscal frente às despesas de pessoal em tempos de crise financeira: os casos do estado do Rio Grande do Sul e da covid-19
}

The mismatch of the Fiscal Responsibility Law in relation to personnel expenses in times of financial crisis: the cases of the state of Rio Grande do Sul and covid-19

\author{
Gustavo da Silva Santanna ${ }^{1}$ \\ Felipe Scalabrin ${ }^{2}$ \\ Jadson Lopes Castanho ${ }^{3}$
}

\section{RESUMO}

A Lei de Responsabilidade Fiscal busca normatizar a gestão do erário, o controle e a prestação de contas públicas. Após duas décadas, porém, é preciso refletir se essa norma ainda atende às finalidades traçadas, especialmente quando surgem situações de crise financeira, ou seja, quando não há, necessariamente, um aumento de despesas, mas sim uma queda (abrupta) na receita. Para tanto, o presente artigo analisará, especificamente, as despesas de pessoal do estado do Rio Grande do Sul, entre os anos de 2015 e 2017, a partir de pareceres emitidos pelo Tribunal de Contas do

\footnotetext{
1 Doutor e mestre pela Universidade do Vale do Rio dos Sinos (Unisinos). Especialista em Direito Ambiental Nacional e Internacional pela Universidade Federal do Rio Grande do Sul (UFRGS) e Direito Público pelo Instituto de Desenvolvimento Cultural (IDC). Professor de graduação do Complexo de Ensino Superior Meridional (IMED), professor da especialização em Direito do Estado da Universidade Federal do Rio Grande do Sul (UFRGS), professor da especialização em Direito Digital, Gestão da Inovação e Propriedade Intelectual da Pontifícia Universidade Católica de Minas Gerais (PUC Minas), professor da Fundação Escola Superior da Defensoria Pública do Rio Grande do Sul (FESDEP), revisor técnico da SAGAH Educação S.A. e procurador do município de Alvorada/RS. E-mail: gssantanna@hotmail.com.

2 Mestre em Direito pela Universidade do Vale do Rio dos Sinos (Unisinos), vinculado à linha hermenêutica, constituição e concretização de direitos. E-mail: fscalabrin@gmail.com.

3 Bacharel em Direito pelo Complexo de Ensino Superior Meridional (IMED). Bacharel em Administração e Tecnólogo em Administração Pública pela Universidade do Sul de Santa Catarina (Unisul). Especialista em Segurança Pública com ênfase na mediação de conflitos e em maçonologia, história e filosofia. Tenente da Brigada Militar do Estado do Rio Grande do Sul. Assessor militar do Tribunal de Contas do Estado do Rio Grande do Sul. E-mail: castanho@tce.rs.gov.br
} 
Estado. Serão, também, matéria de investigação os novos instrumentos legislativos criados em razão do agravamento fiscal gerado pela covid-19. Amparando-se a uma pesquisa bibliográfica e normativa, e baseada no método dedutivo e dialético, conclui-se que as mudanças legislativas efetuadas na Lei de Responsabilidade Fiscal são uma condição de possibilidade para que os administradores públicos tenham critérios mais adequados na avaliação de suas contas em tempos de crise financeira.

Palavras-chave: Covid-19. Crise financeira. Despesas de pessoal. Lei de Responsabilidade Fiscal. Rio Grande do Sul.

\section{ABSTRACT}

The Fiscal Responsibility Law seeks to regulate the treasury management, control and public accountability. After two decades, however, it is necessary to reflect whether the law still meets these purposes, especially when crisis situations arise, that is, when there is not necessarily an increase in expenses, but an (abrupt) decrease in revenue. To this end, this paper will analyze, specifically, personnel expenses of the state of Rio Grande do Sul, between the years 2015 and 2017, based on the opinion of the State Court of Auditors. The new legislative instruments created as a result of the tax increase generated by covid-19 will also be a matter of investigation. Supported by a bibliographic and normative research, based on the deductive and dialectical method, it is concluded that legislative changes made in the Fiscal Responsibility Law are a condition of possibility for public administrators to meet more adequate criteria in the evaluation of their accounts in times of financial crisis.

Keyword: Covid-19. Financial crisis. Personnel expenses. Fiscal Responsibility Law. Rio Grande do Sul.

Recebido: 16-02-2021

Aprovado: 25-03-2021 


\section{INTRODUÇÃO}

A Administração Pública tem a responsabilidade de bem conduzir os interesses do cidadão, uma vez que é por meio dela que se buscam soluções mediante o planejamento governamental para atender aos interesses da coletividade. Os agentes públicos incumbidos da gestão desfrutam de deveres constitucionais que prescrevem princípios indispensáveis no trato da coisa pública e norteiam a atuação dos gestores dos três poderes e nas três esferas de governo.

Quanto ao controle da atividade financeira do Estado, o principal balizador é a Lei Complementar $n^{\circ} 101 / 2000$ (BRASIL, 2000). Ela surge no ordenamento jurídico brasileiro justamente com o objetivo de regrar a gestão do erário, o controle e a prestação de contas públicas. A partir da tríade planejamento, controle e transparência, a Lei de Responsabilidade Fiscal (LRF) ordena a fiel observância do equilíbrio receita versus despesa, do limite de gastos com pessoal e o controle do endividamento público, possuindo como essência a atuação no auxílio da administração para coibir abusos e ações que afrontam a legislação. Trata-se, pois, de mais um instrumento que direciona a Administração Pública para um contexto gerencial (SANTANNA, 2013).

Por outro lado, as dificuldades práticas relacionadas ao cumprimento das regras de responsabilidade fiscal diante de um quadro de queda nas receitas públicas dos estados brasileiros, notadamente no estado do Rio Grande do Sul (a ponto de tornar ainda mais difícil a realização das prestações públicas esperadas pelo texto constitucional), trazem à tona o debate sobre a harmonia e a compatibilidade dessas disposições legais com contextos de crise social. Nesse sentido, traz-se como problema de pesquisa o seguinte questionamento: a Lei de Responsabilidade Fiscal é (está) compatível com os momentos de crise financeira (queda de receita) das administrações? Nesse âmbito, tal questionamento é relevante no sentido 
de que a Lei de Responsabilidade Fiscal foi idealizada considerando-se o aumento de gastos limitados à receita, mas, aparentemente, não cuidou da possibilidade da queda da receita sem o necessário aumento da despesa.

Nesse cenário, busca-se, no presente texto, identificar se a Lei de Responsabilidade Fiscal, a despeito de ser um importante instrumento de planejamento e controle, está adequada a momentos de crise, seja em razão de grave retração econômica, naquilo que se convencionou denominar "calamidade financeira", seja mesmo em virtude de fatos completamente inesperados e com profundo impacto econômico, como a crise sanitária, fruto da pandemia do coronavírus (covid-19), expressamente declarada como "calamidade pública" pelo Congresso Nacional no ano de 2020 (BRASIL, 2020b).

Para identificar com mais clareza a adequação da Lei de Responsabilidade Fiscal, após um breve aceno ao regime jurídico da responsabilidade fiscal e da atuação dos Tribunais de Contas Estaduais, pretende-se analisar a situação fiscal do estado do Rio Grande do Sul antes da pandemia, especialmente a partir do exemplo privilegiado dos gastos de pessoal e da influência decorrente da tentativa de entrada no Regime de Recuperação Fiscal anteriormente elaborado pelo governo federal. Na sequência, busca-se revisar o contexto de origem e ascensão da crise sanitária para, então, perquirir novamente acerca da adequação do regime jurídico da responsabilidade fiscal existente e já em franca modificação.

A partir do exame dos pareceres prévios do Tribunal de Contas do Estado do Rio Grande do Sul, pretende-se apresentar, com elementos concretos, a existência de inconsistências entre a aplicação prática e o texto da Lei de Responsabilidade Fiscal. Dessa forma, será abordada a real situação de fragilidade do erário do estado do Rio Grande do Sul quanto à efetivação dos mecanismos de freios do endividamento público da administração após o advento da Lei de Responsabilidade Fiscal. Utilizaram-se, para a construção do referido estudo, pareceres emitidos 
pelo Tribunal de Contas do Estado do Rio Grande do Sul, bibliografia e legislação pertinente à matéria.

\section{O REGIME JURÍDICO DA RESPONSABILIDADE FISCAL ANTES DA PANDEMIA}

O regime jurídico da responsabilidade fiscal abrange disposições constitucionais (em especial nos arts. 70 e 71) e infraconstitucionais, como a já citada Lei Complementar n ${ }^{\circ}$ 101/2000 (BRASIL, 2000) e tantas outras disposições esparsas. Além disso, o controle das contas públicas se manifesta a partir de três diferentes espécies, todas previstas no texto constitucional. São elas: (a) controle interno; (b) controle externo; (c) controle popular. $\mathrm{O}$ controle externo, que será a matéria de investigação nesse estudo, é exercido pelo Poder Legislativo com o auxílio do Tribunal de Contas dos Estados e, no âmbito federal, configura-se com a participação do Tribunal de Contas da União.

\subsection{ASPECTOS CONSTITUCIONAIS DO CONTROLE FISCAL}

A Constituição Federal apresenta regras e princípios que estão direta e/ou indiretamente relacionados à responsabilidade fiscal da Administração Pública, começando pelos princípios constantes no art. 37, caput (BRASIL, 1988), em que existe a imposição de que a Administração Pública seja guiada pela legalidade, impessoalidade, moralidade administrativa, publicidade e, por fim, pelo princípio da eficiência.

O título VI, capítulo II, da Constituição Federal (BRASIL, 1988), que trata das finanças públicas, traz inúmeras obrigações à administração, com o intuito de manter o equilíbrio financeiro e impedir o crescimento do endividamento público. Nesse sentido, por exemplo, o art. 163 da CF/88 prevê que a lei complementar disporá sobre finanças públicas, dívida pública, concessões de garantias por parte de entes públicos, fiscalização 
financeira da administração, demonstrando a preocupação do constituinte com essa temática, impulsionando o nascimento da Lei de Responsabilidade Fiscal (FALCÃO, 2013). Impende salientar que a exigência de lei complementar para essas áreas reforça a intenção de permanência e de durabilidade do regime jurídico da responsabilidade fiscal, já que essa espécie normativa exige quórum diferenciado (maioria qualificada) para aprovação (SILVA, 2005).

Ainda na perspectiva constitucional, merece ênfase o art. 169 (BRASIL, 1988), destinado ao controle dos gastos com pessoal, a partir da imposição de que sejam observados limites para tal despesa e a vedação para a concessão de aumentos de salários, criação de cargos ou vantagens, sem previsão orçamentária específica e autorização legislativa. O mesmo dispositivo prevê consequências rigorosas, a partir de instrumentos a serem adotados quando os limites impostos não forem observados, como redução de cargos de confiança e exoneração de servidores efetivos não estáveis (art. 169, $\S 2^{\circ}, \S 3^{\circ}$ e $\S 4^{\circ}$ da CF (BRASIL, 1988)).

\subsection{ASPECTOS INFRACONSTITUCIONAIS DA RESPONSA- BILIDADE FISCAL}

Até o final da década de 1990, não havia obrigatoriedade de o gestor público manter um controle efetivo dos atos administrativos, realidade que estimulava o descontrole, pois não precisava focar no equilíbrio receita versus despesa nem havia limite efetivo para gasto com pessoal, tampouco de frear a dívida pública, tornando-se mais latente em anos eleitorais, em que se podia assumir dívidas, deixando a conta para o exercício seguinte, muitas vezes inviabilizando a próxima gestão.

Nesse ínterim, havendo uma necessidade urgente de mudanças estruturais na Administração Pública, objetivando a construção de um ambiente fiscal sustentável e o atendimento dos direitos sociais, foram colocados na pauta nacional a revisão do modelo de federalismo fiscal e o 
aperfeiçoamento da gestão orçamentária com a finalidade de aumentar a eficiência do gasto público. Surge, assim, a Lei de Responsabilidade Fiscal (BRASIL, 2000) no ordenamento jurídico brasileiro, acompanhada de uma série de iniciativas resultantes do Programa de Estabilidade Fiscal, datado de novembro de 1998, como a reforma administrativa e a tributária. Conforme já destacado, todas essas mudanças pretenderam orientar a atuação estatal para um modelo gerencial; onda renovatória que consagra o princípio da boa administração pública (FREITAS, 2009).

No âmbito do Direito Financeiro, cabe notar que essa mudança de cultura não surgiu como uma iniciativa isolada do Brasil, e sim como parte integrante de um movimento internacional marcado pela queda do Muro de Berlim e a crise econômica internacional iniciada na Ásia, tendo sido inspirada basicamente nas experiências da Nova Zelândia (Fiscal Responsibility), do Mercado Comum Europeu (Tratado de Maastricht) e Estados Unidos da América (Budget Enforcement Act), todos na década de 1990 (DOIA, 2016).

O modelo brasileiro voltado à boa governança trouxe uma regulamentação abrangente, discorrendo sobre diretrizes, metas e limites impostos à gestão fiscal, introduzindo na Administração Pública pátria uma série de procedimentos, dirigidos aos três poderes, inovando em normas de transparência e imposição de sanções, obrigando os gestores a se adaptarem às novas formas de controle sobre seus atos no trato com o erário, devendo, a partir de então, prestar contas adequadamente e justificarem suas atuações aos Tribunais de Contas.

De fato, a Lei de Responsabilidade Fiscal exige do gestor o trato com o erário de forma a garantir o seu objetivo primário, ou seja, o atendimento do interesse coletivo, assim como a transparência, tornando de conhecimento da população suas condutas e seus gastos ao gerir a "máquina administrativa", inclusive usando os meios eletrônicos disponíveis para facilitar o controle por parte dos cidadãos, reforçando a previsão constitucional do princípio da publicidade (BEZERRA; BEZERRA; SILVA, 
2011). Desse modo, é incentivado o exercício da cidadania, no momento em que fornece meios para que o cidadão faça parte do controle de seus interesses e possa fiscalizar, monitorar e avaliar as atividades desempenhadas pelos gestores públicos.

Com forte apelo ao princípio da eficiência, a Lei de Responsabilidade Fiscal busca regular o gasto público a fim de tornar a administração orçamentária e financeira do Estado cada vez mais eficiente, controlando as receitas, as despesas e freando o endividamento, proibindo os gastos excessivos em anos de eleição, estimulando uma cultura de boa gestão pública, voltada à coletividade, o que deve se iniciar no berço do gasto público, ou seja, em um planejamento eficiente, que atenda a seus objetivos (CARRA, 2015).

No plano dogmático, a Lei de Responsabilidade Fiscal (BRASIL, 2000) estabelece que serão "consideradas não autorizadas, irregulares e lesivas ao patrimônio público" as despesas que não atendam às previsões dos arts. 16 e 17. Portanto, além da exigência de previsão orçamentária e de autorização legal, existem restrições infraconstitucionais quanto à geração de gastos públicos; tudo a reforçar a responsabilidade fiscal. A previsão, aliás, foi considerada constitucional pelo Supremo Tribunal Federal na Ação Direta de Constitucionalidade n ${ }^{\circ}$ 2.238/DF (BRASIL, 2020i). Os mencionados artigos da Lei de Responsabilidade Fiscal criam um verdadeiro regime jurídico de atuação do gestor e que impõem diretrizes acerca das despesas de ação governamental, das despesas de caráter continuado e, especialmente, das despesas com pessoal.

De fato, os gastos com pessoal, segundo dispõe a Lei Complemen$\operatorname{tar} n^{\circ} 101 / 2000$ (BRASIL, 2000) - Lei de Responsabilidade Fiscal -, recebem um tratamento ainda mais rigoroso, pois abrangem "o somatório dos gastos do ente da Federação com os ativos, os inativos e os pensionistas, relativos a mandatos eletivos, cargos, funções ou empregos, civis, militares e de membros de Poder, com quaisquer espécies remuneratórias, por exemplo, vencimentos e vantagens, fixas e variáveis; subsídios; proventos 
da aposentadoria; reformas e pensões, inclusive adicionais; gratificações; horas extras e vantagens pessoais de qualquer natureza, bem como encargos sociais e contribuições recolhidas pelo ente às entidades de previdência" (art. 18 da referida norma). Até mesmo o "terceirizado", contratado em substituição ao servidor, entra no cômputo pela redação do art. 18, $\S 1^{\circ}$, Lei Complementar $n^{\circ} 101 / 2000$ (BRASIL, 2000). Além disso, essa apuração deve considerar o mês de referência e os doze meses imediatamente anteriores, adotando-se o regime de competência conforme estipula o art.18, §2 $2^{\circ}$, Lei Complementar $n^{\circ} 101 / 2000$ (BRASIL, 2000).

$\mathrm{O}$ art. 19 da Lei de Responsabilidade Fiscal (BRASIL, 2000) estabelece os limites de gastos com pessoal para cada ente da federação, conforme previsto no caput do art. 169 da Constituição Federal (BRASIL, 1988), sendo que, para os estados, o limite de gastos com pessoal não poderá exceder $60 \%$ da Receita Corrente Líquida. E, quando a despesa com pessoal alcançar 95\% desse limite, haverá uma série de imposições restritivas, elencadas nos incisos do art. 22 (BRASIL, 2000d) do mesmo diploma legal, como proibição de concessão de vantagem, aumento ou reajuste; criação de cargos, empregos ou funções; alteração de estruturas de carreira que implique aumento de despesas; provimento de cargo público, admissão ou contratação de pessoal a qualquer título, salvo reposição decorrente de vacância nas áreas de saúde, educação e segurança, entre outras.

Sobreleva pontuar, contudo, que, em razão do enrijecido regime de endividamento previsto na Lei de Responsabilidade Fiscal (BRASIL, 2000), mesmo antes da pandemia decorrente da covid-19, já havia uma verdadeira "válvula de escape". Isso porque a Lei de Responsabilidade Fiscal já antevia que, na hipótese de "calamidade pública", deveriam ser observadas algumas regras especiais, isto é, regras mais flexíveis no controle dos gastos (BRASIL, 2000).

Sob o aspecto legal, a "calamidade pública" compreende "situação anormal, provocada por desastres, causando danos e prejuízos que impli- 
quem o comprometimento substancial da capacidade de resposta do Poder Público do ente federativo atingido ou que demande a adoção de medidas administrativas excepcionais para resposta e recuperação" (BRASIL, 2020h). De outra banda, para que seja viável o emprego do regime financeiro diferenciado, esse estado de calamidade deverá ser reconhecido expressamente pelo Congresso Nacional conforme determina o art. $65 \mathrm{da}$ Lei Complementar $n^{\circ}$ 101/2000 (BRASIL, 2000).

Nota-se a importância do regime especial decorrente de reconhecida calamidade pública, já que, de acordo com o art. 65 da Lei de Responsabilidade Fiscal (BRASIL, 2000): (a) serão suspensas a contagem dos prazos e as disposições estabelecidas nos arts. 23, 31 e 70 da Lei de Responsabilidade Fiscal e; (b) serão dispensados o atingimento dos resultados fiscais e a limitação de empenho prevista no artigo $9^{\circ}$ da mesma norma. Vale lembrar: (i) o art. 23 trata dos limites de despesa com pessoal e das medidas de verificação do cumprimento de metas para eliminar o excedente de despesas; (ii) o art. 31 aborda a recondução da dívida aos limites legalmente autorizados; (iii) o art. 70 também traz uma regra sobre a recondução da dívida com pessoal a patamares exigidos; (iv) o art. $9^{\circ}$ apresenta regras sobre limitação de empenho para o ente que possivelmente não teria recursos para adimplir futuramente suas obrigações.

Destarte, com tantas restrições destinadas à manutenção do sadio ciclo de receitas e despesas do poder público, o ordenamento jurídico ainda prevê intensos instrumentos de controle. O principal deles envolve a atuação dos Tribunais de Contas.

\subsection{ASPECTO FISCALIZATÓRIO POR MEIO DOS TRIBU- NAIS DE CONTAS}

Os Tribunais de Contas brasileiros são órgãos com independência administrativa, financeira e operacional, que têm como função constitu- 
cional auxiliar na fiscalização dos atos da Administração Pública, sobretudo no controle financeiro.

A Constituição Federal (BRASIL, 1988) prevê que o controle externo será exercido pelo Congresso Nacional com o auxílio do Tribunal de Contas da União, ao qual compete apreciar as contas prestadas anualmente pelo presidente, mediante parecer prévio; julgar as contas dos administradores e demais responsáveis (sentido amplo) por dinheiro, bens e valores públicos, e daqueles que derem causa a perda, extravio ou outra irregularidade de que resulte prejuízo ao erário, entre outras competências destinadas ao exercício do controle externo da Administração Pública (art. 71).

Cabe ressaltar que, embora os Tribunais de Contas tenham o papel constitucional de auxiliar o controle externo exercido pelo Poder Legislativo, não há nenhuma hierarquia entre ambos, conforme esclarecido pelo ministro Celso de Melo, na ADIMC no 4.190/RJ (BRASIL, 2009), verbis:

Cabe enfatizar, neste ponto, uma vez mais, na linha da jurisprudência do Supremo Tribunal Federal, que inexiste qualquer vínculo de subordinação institucional dos Tribunais de Contas ao respectivo Poder Legislativo, eis que esses órgãos que auxiliam o Congresso Nacional, as Assembleias Legislativas, a Câmara Legislativa do Distrito Federal e as Câmaras Municipais possuem, por expressa outorga constitucional, autonomia que lhe assegura o autogoverno, dispondo, ainda, os membros que os integram, de prerrogativas próprias, como os predicamentos inerentes à magistratura.

Revela-se inteiramente falsa e completamente destituída de fundamento constitucional a ideia, de todo equivocada, de que os Tribunais de Contas seriam meros órgãos auxiliares do Poder Legislativo. Na realidade, os Tribunais de Contas ostentam posição eminente na estrutura constitucional brasileira, não se achando subordinado, por qualquer vínculo de ordem hierárquica, ao Poder Legislativo, de que não são órgãos delegatários nem organismos de mero assessoramento técnico. 
Dessa forma, pode-se concluir que os Tribunais de Contas são órgãos técnicos, que detêm total autonomia ao exercer seu mister, não estando subordinados a nenhum dos Poderes, sendo caracterizados como órgãos fiscalizadores do poder, auxiliando o controle externo por parte do Legislativo, tendo funções essencialmente de natureza fiscalizatória da atividade financeira do Estado. Além disso são responsáveis por apreciar anualmente as contas dos chefes do Poder Executivo, emitindo o respectivo parecer prévio e julgando as contas de todos aqueles que lidam com o erário, tendo suas condenações, eficácia de título executivo, devendo ser lançados como dívida ativa, pretendendo ressarcir os cofres via execução fiscal (SANTANNA, 2015).

Em verdade, o presidente da República, os governadores e os prefeitos têm a obrigação constitucional e legal de prestar contas anualmente, das quais, e de posse das informações apresentadas, os Tribunais de Contas efetuam uma análise minuciosa e emitem os chamados pareceres prévios, os quais são enviados aos respectivos legislativos para que subsidiem a atuação precípua desse Poder, que é efetuar o controle externo e julgar as contas dos governantes. De fato, a competência para apreciar as contas dos gestores é do próprio Poder Legislativo, com o auxílio dos Tribunais de Contas (BRASIL, 2016).

Embora o parecer prévio das contas de governo se assemelhe ao processo de julgamento de contas dos demais gestores públicos, com este procedimento não pode ser confundido, uma vez que não há investigação ou perquirição da responsabilidade pessoal do chefe do Poder Executivo (LIMA; OLIVEIRA; CAMARGO, 2018). E, apesar do caráter opinativo, o parecer prévio tem importante papel político e colabora com a transparência na condução dos gastos públicos. 


\section{A SITUAÇÃO FISCAL DO ESTADO DO RIO GRANDE DO SUL ANTES DA PANDEMIA}

A situação fiscal do estado do Rio Grande do Sul antes da pandemia, em um contexto que já era de crise no equilíbrio receita versus despesa, pode ser um excelente indicativo dos desafios entre a prática orçamentária e as previsões legais atinentes ao tema. E o exemplo privilegiado envolve justamente os gastos com pessoal.

Ao se analisar a série histórica no cenário do estado do Rio Grande do Sul (RS), levando em consideração o método de aferição utilizado pelo Tribunal de Constas do Estado do Rio Grande do Sul, que é divergente do adotado pela Secretaria do Tesouro Nacional (BRASIL, 2020j), vislumbra-se que, no ano de 2015, a despesa com pessoal no estado representou $53 \%$ da despesa total no exercício, sendo que, desse montante, $21,97 \%$ referem-se a pessoal ativo, e 26,32\% a inativos e pensionistas (RIO GRANDE DO SUL, 2016). Em 2016, representou 54\% da despesa total, sendo $21,62 \%$ ativos e $28,18 \%$ inativos (RIO GRANDE DO SUL, 2017b). E, em 2017, essa despesa também representou 54\% da despesa total, sendo $20,81 \%$ para ativos e $28,92 \%$ para inativos e pensionistas (RIO GRANDE DO SUL, 2018). Certamente, a despesa com pessoal e encargos sociais é um dos maiores entraves de uma política de ajuste fiscal, principalmente por demonstrar uma curva ascendente no número de inativos em relação aos servidores ativos (LUQUE; SILVA, 2004).

Assim, aspirando manter o equilíbrio fiscal verdadeiro, a Lei de Responsabilidade Fiscal criou um parâmetro chamado Receita Corrente Líquida (RCL), sendo o somatório das receitas tributárias arrecadadas, excluindo as transferências constitucionais, tendo seus critérios de mensuração criados pela própria lei, e, esta, associada à disponibilidade real de recursos para fixar despesas.

Conforme demonstram os pareceres prévios emitidos pelo Tribunal de Contas (RIO GRANDE DO SUL, 2016, 2017a, 2018), o gasto com 
pessoal totalizou, em 2015, o percentual de 79,54\%; em 2016, 73,10\%; e, em 2017, 77,30\% da Receita Corrente Líquida. Note-se que estão acima do limite imposto na legislação. Ocorre que, nesta análise do limite máximo de gastos com pessoal em relação às metas fiscais da Lei de Responsabilidade Fiscal (60\% segundo determina o art. 19, II, da Lei Complemen$\operatorname{tar}^{\circ}$ 101/2000 (BRASIL, 2000)), o Tribunal de Contas gaúcho excluiu do cálculo o imposto de renda retido na fonte e contribuições previdenciárias, baixando o percentual para $69,36 \%$ em $2015,62,24 \%$ em 2016 e $65,42 \%$ no ano de 2017. Ainda assim, posteriormente, suprimiu também o gasto com pensões, reduzindo ainda mais o percentual da despesa para $57,48 \%$, $51,95 \%$ e $54,95 \%$ da Receita Corrente Líquida, respectivamente aos exercícios de 2015, 2016 e 2017, levando os gastos, que a princípio estavam acima do teto imposto pela Lei de Responsabilidade Fiscal, para limites aceitáveis pela norma.

Dessa forma, o Tribunal de Contas do Estado do Rio Grande do Sul, ao exercer sua prerrogativa de fiscal dos ditames da Lei de Responsabilidade Fiscal, adotou uma matriz de cálculo que flexibilizou a aferição dos gastos com pessoal em atendimento aos limites impostos pela norma. Para melhor elucidar o ponto e aprofundar o exame da crise no contexto das contas do estado gaúcho, cumpre realizar um breve exame dos pareceres prévios referentes aos anos de 2015, 2016 e 2017, bem como da tentativa de renegociação da dívida com a União que ocorreu antes da pandemia.

\subsection{AS CONTAS REFERENTES AO ANO DE 2015}

No parecer prévio do ano de 2015 (RIO GRANDE DO SUL, 2016), vislumbra-se o orçamento previsto e executado, demonstrando o déficit orçamentário do estado do Rio Grande do Sul, conforme tabela a seguir: 
Tabela 1 - Orçamento 2015 do estado do Rio Grande do Sul

\begin{tabular}{c|c|c|c}
\hline Orçamento 2015 (Em R\$ mil) & $\begin{array}{c}\text { Receita } \\
\text { (A) }\end{array}$ & $\begin{array}{c}\text { Despesa (*) } \\
\text { (B) }\end{array}$ & $\begin{array}{c}\text { Resultado } \\
\text { (A-B) }\end{array}$ \\
\hline 1. Previsão & 47.978 .310 & 47.978 .304 & 6 \\
\hline 2. Execução & 40.980 .681 & 45.558 .909 & 4.578 .228 \\
\hline 3. Diferença (2-1) & 6.997 .629 & 2.419 .395 & 4.578 .234 \\
\hline $\begin{array}{c}\text { 4. Resultado obtido nas operações intraorça- } \\
\text { mentárias }\end{array}$ & 9.232 .454 & 9.596 .742 & 364.288 \\
\hline 5. Resultado orçamentário (3+4) - DÉFICIT & & & 4.942 .516 \\
\hline
\end{tabular}

Fonte: Rio Grande do Sul (2016).

Conforme se verifica na tabela, embora haja uma previsão orçamentária com equilíbrio receita versus despesa, na prática, durante a execução, houve um déficit na ordem de 4.578.234 bilhões de reais, somando-se o resultado das operações intraorçamentárias (ocorre quando órgãos da Administração Pública efetuam transações entre si, ou seja, a despesa de um é a receita do outro, o que, em geral, acontece quando os órgãos empenham recursos para ingressarem no IPERGS, objetivando o custeio da previdência e assistência à saúde), sendo que, levando em consideração os ajustes necessários, incluindo as despesas pagas sem empenho (precatórios, bloqueios judiciais para saúde e requisições de pequeno valor - RPV) que somaram R\$ 1.120 bilhão, há um déficit no ano de 2015 na ordem de R\$ 5.912 bilhões.

O desequilíbrio, neste caso, não decorreu de excesso de gastos, mas sim da própria crise financeira global, com grande estagnação econômica, impactando diretamente as contas públicas, como, aliás, levantou o relator do parecer prévio, Conselheiro Estilac Xavier (RIO GRANDE DO SUL, 2016). Nesse cenário de verdadeira dificuldade global, "considerando a conjuntura que decorre do agravamento das crises política e econômica pela qual passou e passa o Brasil, cujos resultados podem ser observados em todos os níveis de governo e na própria sociedade como um todo", o Tribunal de Contas do Estado foi favorável à aprovação das contas, o que demonstrou a sensibilidade do colegiado para com o tema (RIO GRANDE DO SUL, 2016). 


\subsection{AS CONTAS REFERENTES AO ANO DE 2016}

No parecer prévio do ano de 2016 (RIO GRANDE DO SUL, 2017a), tal como no ano anterior, vislumbra-se o orçamento previsto e executado, demonstrando o déficit orçamentário do estado do Rio Grande do Sul, conforme tabela a seguir:

Tabela 2 - Orçamento 2016 do estado do Rio Grande do Sul

\begin{tabular}{c|c|c|c}
\hline Orçamento 2016 (Em R\$ mil) & $\begin{array}{c}\text { Receita } \\
\text { (A) }\end{array}$ & $\begin{array}{c}\text { Despesa (*) } \\
\text { (B) }\end{array}$ & $\begin{array}{c}\text { Resultado } \\
\text { (A-B) }\end{array}$ \\
\hline 1. Previsão & 52.373 & 52.373 & - \\
\hline 2. Execução & 47.011 & 47.020 & 9 \\
\hline 3. Diferença (2-1) & -5.362 & -5.353 & -9 \\
\hline 4. Resultado obtido nas operações intraorçamentárias & 10.333 & 10.467 & -134 \\
\hline 5. Resultado orçamentário (3+4) - DÉFICIT & & & -143 \\
\hline
\end{tabular}

Fonte: Rio Grande do Sul (2017a).

Embora haja uma previsão orçamentária com equilíbrio receita versus despesa, na prática, durante a execução, houve um déficit na ordem de 143 milhões de reais, somando-se o resultado das operações intraorçamentárias, sendo que, levando em consideração os ajustes necessários, incluindo as despesas pagas sem empenho que somaram R $\$ 752.8$ milhões, há um déficit no ano de 2016 na ordem de R\$ 1.04 bilhões.

Não obstante, este é considerado o menor déficit desde o exercício de 2010, o que não significa melhora nos problemas fiscais enfrentados, pois os resultados foram influenciados pelo ingresso de receitas extraordinárias, como a "venda" da folha de pagamento do funcionalismo público para o Banrisul.

Assim como sucedeu no parecer do exercício de 2015, embora se reconheçam os problemas oriundos do não cumprimento dos ditames legislativos, o voto do relator, Conselheiro Iradir Pietroski, foi no senti- 
do de emitir um parecer favorável às contas do governador, declarando atendidos os limites impostos pela Lei de Responsabilidade Fiscal (RIO GRANDE DO SUL, 2017).

\subsection{AS CONTAS REFERENTES AO ANO DE 2017}

No parecer prévio do ano de 2017, seguindo o constante déficit orçamentário dos exercícios anteriores, vislumbra-se um orçamento que não condiz com a realidade executada, sendo o equilíbrio receita versus despesa mera peça de ficção, o que dificulta o ajuste das contas públicas, pois há uma superestimação de receita para permitir aumento de despesas que historicamente é subestimado (NUNES; NUNES, 2014), demonstrado na tabela a seguir:

Tabela 3 - Orçamento 2017 do estado do Rio Grande do Sul

\begin{tabular}{c|c|c|c}
\hline Orçamento 2017 (Em RS mil) & $\begin{array}{c}\text { Receita } \\
\text { (A) }\end{array}$ & $\begin{array}{c}\text { Despesa (*) } \\
\text { (B) }\end{array}$ & $\begin{array}{c}\text { Resultado } \\
\text { (A-B) }\end{array}$ \\
\hline 1. Previsão & $51.404,88$ & $51.404,88$ & - \\
\hline 2. Execução & $48.545,5$ & $50.185,2$ & $1.639,7$ \\
\hline 3. Diferença (2-1) & $-2.859,3$ & $-1.219,6$ & $1.639,7$ \\
\hline 4. Resultado obtido nas operações intraorçamentárias & $12.262,0$ & $12.291,0$ & -29 \\
\hline 5. Resultado orçamentário (3+4) - DÉFICIT & & & $1.668,7$ \\
\hline
\end{tabular}

Fonte: Rio Grande do Sul (2018).

Conforme demonstra a Tabela 3, embora haja uma previsão orçamentária com equilíbrio receita versus despesa, na prática, durante a execução, houve déficit na ordem de R $\$ 1.668,70$ bilhões, sendo que, levando em consideração os ajustes necessários, incluindo as despesas pagas sem empenho, há um déficit no ano de 2017 na ordem de 1.84 bilhões de reais.

No parecer prévio do ano de 2017, ao final de uma análise criteriosa, por meio da qual são abordados os reflexos da crise fiscal que assolou o estado do Rio Grande do Sul, o crescente endividamento público, os crité- 
rios para adesão ao Regime de Recuperação Fiscal, o relator, conselheiro Pedro Figueiredo, manifestou-se pela emissão do parecer prévio favorável à aprovação das contas do governador, recomendando que o Poder Executivo viabilizasse a fiscalização do controle externo sobre a Administração Tributária, principalmente sobre a fiscalização, procedimentos de autos de lançamentos, extinções de crédito e controle de concessões e fruição de benefícios fiscais, incluídos os Termos de Acordo para liberação de créditos do ICMS - Exportação, ou seja, as isenções e renúncias de receita, incluindo as provenientes da Lei Kandir (RIO GRANDE DO SUL, 2018).

\subsection{A TENTATIVA DE RENEGOCIAÇÃO DA DÍVIDA COM A UNIÃO}

O cenário de endividamento do estado do Rio Grande do Sul, nos anos anteriores à pandemia, revelou um quadro fático de difícil harmonia com a legislação vigente. Com efeito, não se tratou apenas do excesso de despesas que ficam sob o crivo das metas da Lei de Responsabilidade Fiscal, mas também da gradativa redução da arrecadação fiscal. Em 2015, houve uma redução na ordem de $2,96 \%$ da receita proveniente do ICMS em comparação com os anos anteriores, sendo que o ICMS representou $64 \%$ de todo o ingresso de recursos nos cofres do estado do Rio Grande do Sul em 2015; em 2016, - 63\%; e, em 2017, - 65\% (RIO GRANDE DO SUL, 2016, 2017a, 2018).

No estado do Rio Grande do Sul, pesaram também as perdas líquidas decorrentes da Lei Kandir. A título de exemplificação, devido à falta de recomposição adequada por parte da União, somente no ano de 2015 a perda de arrecadação foi na ordem de R\$ 1.348 bilhões; em 2016, de R\$ 1,18 bilhões; e, em 2017, de 1,278 bilhões, perfazendo um montante nominal de 11,62 bilhões de reais nos últimos 16 anos, atualizados pelo IGPM/DI de julho de 2017 (RIO GRANDE DO SUL, 2018). As perdas lí- 
quidas entre os anos de 1996 e 2016 somaram mais de 50 bilhões de reais.

Para se vislumbrar a degradação fiscal do estado gaúcho, no ano de 2011, as despesas alcançaram 102,31\% da Receita Corrente Líquida, totalizando em reais a soma de aproximadamente 640 milhões. Já em 2015, com o agravamento da crise, esse percentual de despesas chegou a 113,83\%, refletindo um déficit de aproximadamente 4 bilhões de reais. Em 2016, as despesas alcançaram 99,08\% da Receita Corrente Líquida, gerando um saldo positivo de R\$ 319 milhões, mas isso devido ao não pagamento mensal dos serviços da dívida com a União, calculados em 2,38 bilhões de reais, a redução do quadro de pessoal, a imposição de medidas de contenção de gastos, o aumento das alíquotas de ICMS (não atingiu a previsão, puxado pelo baixo desempenho da atividade econômica) e a "venda" da folha de pagamentos dos servidores ao Banrisul. Em 2017, as despesas alcançaram 104,71\% da Receita Corrente Líquida, totalizando 1.566 bilhão de reais (RIO GRANDE DO SUL, 2018).

Devido ao cenário de endividamento dos estados brasileiros, que em boa parte recorreram ao governo federal buscando uma renegociação de suas dívidas, ou seja, socorro financeiro para evitar o colapso das finanças públicas, foi editada, em 19 de maio de 2017, a Lei Complementar $n^{\circ} 159 / 2017$ (BRASIL, 2017), trazendo o regramento para que os estados fizessem a adesão ao Regime de Recuperação Fiscal.

O regime de recuperação é alicerçado pelo princípio da sustentabilidade econômico-financeira e busca corrigir os desvios que levaram ao desequilíbrio das contas públicas, determinando medidas emergenciais e reformas institucionais que devam ser primeiramente implementadas pela unidade federativa que deseja aderir ao Plano, aspirando reduzir o déficit das contas públicas a partir de uma "reestruturação" administrativa, revendo carreiras, freando despesas com pessoal, trabalhando pelo reequilíbrio financeiro.

Para o estado se habilitar ao regime de recuperação, deve(ria) primeiro preencher alguns requisitos, como ter sua Receita Corrente Líqui- 
da menor do que sua dívida consolidada, despesas líquidas com pessoal, somadas aos juros e à amortização que representassem no mínimo 70\% dessa receita.

Dessa forma, o estado que aderir ao plano de recuperação deixa de pagar sua dívida com a União pelo prazo de vigência do plano, ficando obrigado a retomar o pagamento das prestações de acordo com critérios estabelecidos pelo Ministério da Fazenda. Para tanto, a Lei dispensou os requisitos legais exigidos para a contratação com a União e a verificação dos requisitos exigidos pela Lei de Responsabilidade Fiscal.

Conforme consta no relatório do parecer prévio do ano de 2017 (RIO GRANDE DO SUL, 2018), da lavra do relator conselheiro Pedro Henrique Poli de Figueiredo, o estado do Rio Grande do Sul encaminhou proposta para a Secretaria do Tesouro Nacional para se habilitar ao plano de recuperação e obteve uma resposta negativa por não atender ao requisito de comprometimento dos gastos com pessoal em, no mínimo, 70\% da Receita Corrente Líquida. Isso porque, de acordo com a metodologia de cálculo adotada pelo Tribunal de Contas do Estado (RIO GRANDE DO SUL, 2018), as despesas com pessoal somadas com juros e amortizações representavam $57,42 \%$ da Receita Corrente Líquida, não atingindo o mínimo exigido pela norma.

Buscando se adequar para aderir ao programa, o Executivo alegou que os critérios adotados pelo Tribunal de Contas Estadual iriam de encontro à Lei de Responsabilidade Fiscal - LRF, contrariando os critérios da Secretaria do Tesouro Nacional. O Tribunal de Contas, por sua vez, respondeu que, pelo critério adotado pela Corte de Contas, o estado atingiu o percentual de $57,42 \%$ de comprometimento da Receita Corrente Líquida em 2016 e que, se o critério adotado fosse o da Secretaria do Tesouro Nacional, esse percentual passaria para $68,01 \%$ de comprometimento (RIO GRANDE DO SUL, 2018).

Já no documento emitido pelo estado à Secretaria do Tesouro Nacional (RIO GRANDE DO SUL, 2018), pleiteava-se a exclusão do ingresso 
de 1,28 bilhões de reais dos recursos provenientes da "venda" da folha de pagamentos para o Banrisul, por ser receita extraordinária. Assim, de acordo com o critério da Secretaria do Tesouro Nacional, o percentual de comprometimento chegaria a 70,55\%, atingindo, portanto, o mínimo exigido.

Nas discussões sobre a inclusão do estado do Rio Grande do Sul no Regime de Recuperação Fiscal, verificou-se a divergência entre a matriz de cálculos para aferir a Receita Corrente Líquida e seus comprometimentos entre a Secretaria do Tesouro Nacional e os Tribunais de Contas. Em um primeiro momento, exige-se que todas as Cortes de Contas brasileiras utilizem a matriz definida pela referida Secretaria, e não critérios próprios. A divergência gerou uma diferença considerável de resultados:

Tabela 4 - Cálculo da Receita Corrente Líquida (Critérios TCE e STN)

\begin{tabular}{l|c|c}
\hline & Critério TCE & Critério STN \\
\hline 1. Receita Bruta (sem o retorno do FUNDEB) & $\mathbf{4 8 . 2 0 8 . 0 5 5 . 2 1 1 , 2 7}$ & $\mathbf{4 8 . 2 0 8 . 0 5 5 . 2 1 1 , 2 7}$ \\
\hline 1.1 (-) Contribuição ao FUNDEB & $5.339 .060 .686,97$ & $5.339 .060 .686,97$ \\
\hline 1.2 (+) Retorno do FUNDEB & $4.158 .145 .416,00$ & $4.158 .145 .416,00$ \\
\hline 1.3 (-) Receita rendimento negativo Fundoprev & $16.120 .212,23$ & $16.120 .212,23$ \\
\hline 2. Receita Consolidada (1-1.1+1.2-1.3) & $\mathbf{4 7 . 0 1 1 . 0 1 9 . 7 2 8 , 0 7}$ & $\mathbf{4 7 . 0 1 1 . 0 1 9 . 7 2 8 , 0 7}$ \\
\hline 2.1 (-) Receita de Capital & $561.464 .651,56$ & $561.464 .651,56$ \\
\hline 3. Receita Corrente (2-2.1) & $\mathbf{4 6 . 4 4 9 . 5 5 5 . 0 7 6 , 5 1}$ & $\mathbf{4 6 . 4 4 9 . 5 5 5 . 0 7 6 , 5 1}$ \\
\hline 4. Deduções para apuração da RCL & $\mathbf{1 0 . 8 6 1 . 2 9 3 . 2 1 7 , 3 9}$ & $\mathbf{1 0 . 8 6 1 . 2 9 3 . 2 1 7 , 3 9}$ \\
\hline 4.1 (-) Transferências Constitucionais a Municípios & $8.920 .589 .030,40$ & $8.920 .589 .030,40$ \\
\hline 4.2 (-) Contribuição Previdenciária dos Servidores & $1.649 .068 .511,63$ & $1.649 .068 .511,63$ \\
\hline 4.3 (-) Compensação Financeira entre Regimes Previdenciários & $49.262 .933,73$ & $49.262 .933,73$ \\
\hline 4.4 (-) Anulação de Restos a Pagar & $150.016 .632,69$ & $150.016 .632,69$ \\
\hline $\begin{array}{l}\text { 4.5 (-) Saldo entre a receita e a perda c/remun. investim. renda } \\
\text { fixa Fundoprev }\end{array}$ & $92.356 .108,94$ & $92.356 .108,94$ \\
\hline 5. Subtotal RCL (3 - 4) & $35.588 .261 .859,12$ & $35.588 .261 .859,12$ \\
\hline 6. (-) IRRF Ativos, Inativos e Pensionistas & $\mathbf{2 . 1 1 4 . 2 7 9 . 7 1 9 , 7 9}$ & - \\
\hline 7. (+) Retenção/perda do FUNDEB (1.1-1.2) & $\mathbf{1 . 1 8 0 . 9 1 5 . 2 7 0 , 9 7}$ & - \\
\hline 8. Receita Corrente Líquida (5-6+7) & $\mathbf{3 4 . 6 5 4 . 8 9 7 . 4 1 0 , 3 0}$ & $\mathbf{3 5 . 5 8 8 . 2 6 1 . 8 5 9 , 1 2}$ \\
\hline
\end{tabular}
Fonte: Rio Grande do Sul (2017b). 
A divergência de valores na ordem de quase um bilhão de reais refere-se à exclusão do imposto de renda retido na fonte, bem como à inclusão do valor referente ao Fundeb, conforme entendimento da Corte de Contas Gaúcha.

Tabela 5 - Cálculo das Despesas de Pessoal (Critérios TCE e STN)

\begin{tabular}{l|c|c}
\hline & Critério TCE & Critério STN \\
\hline 1. Despesa com Pessoal Ativo & $\mathbf{1 0 . 9 2 1 . 2 6 6 . 0 3 3 , 7 8}$ & $\mathbf{1 1 . 9 9 4 . 3 8 3 . 9 8 3 , 0 1}$ \\
\hline 1.1 Pessoal Ativo & $11.412 .269 .345,96$ & $11.412 .269 .345,96$ \\
\hline 1.2 Abono Família & $39.081 .509,38$ & $39.081 .509,38$ \\
\hline 1.3 Obrigações Patronais & $2.586 .292 .736,99$ & $2.586 .292 .736,99$ \\
\hline 1.4 (-) Imposto de Renda Retido na Fonte & $1.073 .117 .949,23$ & - \\
\hline 1.5 (-) Sentenças Judiciais & $898.194 .781,22$ & $898.194 .781,22$ \\
\hline 1.6 (-) Despesas de Exercícios Anteriores - Ativos & $265.859 .411,05$ & $265.859 .411,05$ \\
\hline 1.7 (-) Demais Exclusões & $879.205 .417,05$ & $879.205 .417,05$ \\
\hline 2. Emater & $\mathbf{1 6 4 . 2 0 0 . 0 0 0 , 0 0}$ & $\mathbf{1 6 4 . 2 0 0 . 0 0 0 , 0 0}$ \\
\hline 3. Despesa com Inativos & $\mathbf{7 . 0 7 0 . 0 6 2 . 0 8 0 , 9 4}$ & $\mathbf{7 . 6 2 7 . 5 6 1 . 3 7 9 , 7 0}$ \\
\hline 3.1 Inativos & $10.765 .347 .842,86$ & $10.765 .347 .842,86$ \\
\hline 3.2 Abono Família - Inativos & $10.313 .605,86$ & $10.313 .605,86$ \\
\hline 3.3 Obrigações Patronais - Inativos & $7.120 .144 .001,30$ & $7.120 .144 .001,30$ \\
\hline 3.4 (-) Contribuição dos Segurados & $1.190 .966 .624,25$ & $1.524 .303 .004,07$ \\
\hline 3.5 (-) Imposto de Renda Retido na Fonte & $890.835 .678,58$ & - \\
\hline 3.6 (-) Compensação Financeira - CF, artigo 201 & $49.262 .933,73$ & $49.262 .933,73$ \\
\hline 3.7 (-) Despesas de Exercícios Anteriores - Inativos & $250.404 .976,87$ & $250.404 .976,87$ \\
\hline 3.8 (-) Inativos com Recursos Vinculados & $8.444 .273 .155,65$ & $8.444 .273 .155,65$ \\
\hline 4. Despesa com Pensionistas & - & $\mathbf{2 . 6 7 3 . 6 1 2 . 0 2 3 , 2 1}$ \\
\hline $\mathbf{5 . ~ D e s p e s a ~ T o t a l ~ c o m ~ P e s s o a l ~ ( 1 + 2 + 3 + 4 ) ~}$ & $\mathbf{1 8 . 1 5 5 . 5 2 8 . 1 1 4 , 7 2}$ & $\mathbf{2 2 . 4 5 9 . 7 5 7 . 3 8 5 , 9 2}$ \\
\hline
\end{tabular}

Fonte: Rio Grande do Sul (2017b).

Por outro lado, na apuração da despesa com pessoal, a divergência ficou em aproximadamente quatro bilhões de reais, a menor no critério do Tribunal de Contas do Estado, em que exclui o imposto de renda retido na fonte e há a não inclusão da despesa com pensionistas e consequentes 
exclusões das contribuições ao regime de previdência. Tais flexibilizações são fruto das dificuldades impostas aos órgãos de controle por problemas de economia política e crise fiscal (PONTES, 2019).

\section{A CALAMIDADE SANITÁRIA E SEU IMPACTO NO ENDI- VIDAMENTO ESTADUAL}

Em meados de dezembro de 2019, começaram a surgir notícias sobre o coronavírus (Sars-cov-2), também conhecido como covid-19. O vírus rapidamente se espalhou pelo mundo e, em 11 de março de 2020, a Organização Mundial da Saúde (OMS) elevou o surto em nível de pandemia mundial, situação essa que gera reflexos ainda imensuráveis na ordem social e econômica, assim como no ordenamento político-jurídico como um todo, desafiando a administração pública a adotar medidas excepcionais para fazer frente aos novos desafios, uma vez que as ferramentas já existentes no Direito Administrativo se mostram ineficientes (LACERDA, 2020).

Em virtude dessa situação extraordinária, o governo federal e alguns estados e municípios editaram uma série de leis/decretos instituindo situação de calamidade pública para atender ao art. 65 da Lei de Responsabilidade Fiscal e, assim, flexibilizar as metas e os prazos previstos no diploma legal. O decreto de calamidade pública foi algo inédito no âmbito federal.

O Decreto Legislativo $n^{\circ} 6$ (BRASIL, 2020b) do Congresso Nacional reconheceu:

exclusivamente para os fins do artigo 65 da Lei Complementar $\mathrm{n}^{\mathrm{o}} 101$, de 4 de maio de 2000, notadamente para as dispensas do atingimento dos resultados fiscais previstos no artigo $2^{\circ}$ da Lei $n^{\circ} 13.898$, de 11 de novembro de 2019, e da limitação de empenho de que trata o artigo $9^{\circ}$ da Lei Complementar $\mathrm{n}^{\circ} 101$, de 4 de maio de 2000, a ocorrência do estado de calamidade pública, com efeitos até 31 de dezembro de 2020, nos termos da solicitação do Presidente da República encaminhada por meio da Mensagem $n^{\circ}$ 93, de 18 de março de 2020 (artigo $1^{\circ}$ ). 
É de se lembrar, contudo, que governos estaduais já haviam utilizado o reconhecimento de "calamidade financeira" para justificar o afastamento das travas previstas na Lei de Responsabilidade Fiscal. Nesse sentido, por exemplo, em virtude da crise fiscal enfrentada nos anos de 2015 e 2016, em decorrência da queda da arrecadação, conforme demonstrado anteriormente, entre eles o estado do Rio Grande do Sul, que editou o Decreto ${ }^{\circ} 53.303$, em 21 de novembro daquele ano, devido ao estado de calamidade financeira (ABRAHAM, 2020). O decreto de então era baseado na queda estimada do Produto Interno Bruto em torno de 7\% entre os anos de 2015 e 2016, trazendo, assim, trágicas consequências para a arrecadação de tributos; também estava alicerçado no aumento dos gastos com pessoal, com a gravidade da crise econômica e com a necessidade de garantir a prestação dos serviços públicos essenciais.

A calamidade sanitária, contudo, é algo inédito e poderá se traduzir em uma grave crise econômica, com a exponencial elevação dos gastos públicos em curto e em médio prazos, além de uma provável redução na arrecadação em razão da drástica redução da atividade econômica de inúmeros agentes do mercado. Não bastando o avassalador número de vidas ceifadas, a própria saúde fiscal do ente público será colocada à prova.

\section{O REGIME JURÍDICO DA RESPONSABILIDADE FISCAL DURANTE A PANDEMIA}

Durante a pandemia, a proliferação desenfreada de atos normativos criou um verdadeiro mosaico de regras destinadas à proteção da sociedade, da saúde, da economia e, também, das contas públicas.

É ilustrativa, nesse ponto, a aprovação de uma renda básica para fazer frente ao grave quadro de desemprego por meio do assim chamado "auxílio emergencial", fruto da Lei no 13.982/2020 (BRASIL, 2020c). Devido ao quase fechamento total da indústria, comércios e serviços (exceto os declarados essenciais), o governo federal, com a adoção do auxílio 
emergencial, antecipou recursos na cifra de 700 bilhões de reais em apenas três meses, para minimizar os impactos sobre a saúde e a economia. Segundo o ministro da Economia, esses recursos deveriam ser utilizados ao longo de oito anos de governo, mas, devido à gravidade da situação, foram disponibilizados em poucos meses (GURGEL, 2020).

Especificamente sobre a responsabilidade fiscal, a quantidade de alterações normativas reforça a presença de um descompasso da Lei de Responsabilidade Fiscal com situações de crise econômica. Algumas dessas mudanças merecem especial destaque.

A Emenda Constitucional $n^{\circ}$ 106/2020 (BRASIL, 2020e) estabeleceu um regime extraordinário fiscal, financeiro e de contratações para o enfrentamento da pandemia. Esse regime extraordinário, entretanto, foi destinado à União ( $\operatorname{art.} 1^{\circ}$ ), para que pudesse adotar processos simplificados de contratação de pessoal, de obras, de serviços e de compras em caráter temporário e emergencial sem a observância do art. $169, \S^{\circ}$ da Constituição Federal (art. $2^{\circ}$ ).

A Lei $n^{\circ} 13.983 / 2020$ (BRASIL, 2020d), por sua vez, preocupada com as exigências da Lei de Responsabilidade Fiscal, alterou a Lei Orçamentária Anual de 2020 para ampliar o déficit do setor público para o ano de 2020, flexibilizando e ampliando as metas fiscais. A Lei no 13.999/2020 (BRASIL, 2020f) instituiu o programa nacional de apoio às microempresas e às empresas de pequeno porte (PRONAMPE) para viabilizar linhas de crédito e, desse modo, minimizar o inevitável fechamento de postos de trabalho e a consequente estagnação econômica no período posterior à pandemia. A Lei Complementar no 173/2020 (BRASIL, 2020g) alterou a Lei de Responsabilidade Fiscal ao estabelecer o Programa Federativo de Enfrentamento à Covid-19. Em seu art. $1^{\circ}$, a norma estabelece o programa, nos termos do art. 65 da Lei Complementar no 101/2000 (BRASIL, 2000), para o exercício financeiro de 2020, para suspensão dos pagamentos das dívidas contratadas entre a União e demais entes da federação, reestruturando as operações de crédito, bem como estabelece a transfe- 
rência voluntária da União na forma de auxílio financeiro para o combate à pandemia. Também dispensa os limites de gastos/fiscais, condições e demais restrições para quem não atingir as metas previstas na Lei de Responsabilidade Fiscal, buscando viabilizar a contratação e o adiantamento de operações de crédito, concessões de garantias e o recebimento de transferências voluntárias (BRASIL, 2020g).

Mais recentemente, a Lei Complementar $n^{\circ}$ 178/2021 (BRASIL, 2021) alterou um amplo feixe de leis, inclusive a Lei de Responsabilidade Fiscal, para estabelecer o Programa de Acompanhamento e Transparência Fiscal. O citado programa estabelece metas e compromissos para o estado, o Distrito Federal e o município, e a sua adesão pelos entes da federação proporciona a pactuação no Plano de Promoção do Equilíbrio Fiscal com a União, para eventual adesão ao Regime de Recuperação Fiscal (art. $1^{\circ}$, $6^{\circ}$ ).

Ademais, a Lei Complementar n. ${ }^{\circ}$ 178/2021 (BRASIL, 2021) ainda estabeleceu "medidas de reforço à responsabilidade fiscal" (Capítulo IV). No entanto, entre as disposições, ela prevê que estarão suspensos os prazos e as previsões do art. 23 da Lei de Responsabilidade Fiscal no ano de 2021. O art. 23 da Lei de Responsabilidade Fiscal (BRASIL, 2000) é justamente a previsão legal que detalha o controle das despesas com pessoal e a exigência de eliminação do excedente de gastos em prazos determinados.

Com a suspensão dos prazos previstos na Lei de Responsabilidade Fiscal, a Lei Complementar n ${ }^{\circ}$ 178/2021 (BRASIL, 2021) traz uma verdadeira "segunda chance" para o poder público restaurar a degradação das contas públicas ao estabelecer que o excesso deve ser eliminado "à razão de, pelo menos, $10 \%$ (dez por cento) a cada exercício a partir de 2023, por meio da adoção, entre outras, das medidas previstas nos artigos 22 e 23 daquela Lei Complementar, de forma a se enquadrar no respectivo limite até o término do exercício de 2032" (art. 15).

A Lei Complementar $n^{\circ}$ 178/2021 (BRASIL, 2021) também encerrou, de uma vez por todas, o debate em torno da matriz de cálculo dos gas- 
tos com pessoal ${ }^{4}$. Isso porque agora está expressamente previsto que, para a apuração da despesa total com pessoal, "será observada a remuneração bruta do servidor, sem qualquer dedução ou retenção, ressalvada a redução para atendimento ao disposto no artigo 37, inciso XI, da Constituição Federal" (art. 18, §3 (BRASIL, 2000)).

Reitere-se que o Tribunal de Contas do Estado do Rio Grande do Sul já excluía as deduções e as retenções do cálculo dos gastos com pessoal. Em contrapartida, não serão computadas nos limites de despesas com pessoal a partir da Receita Corrente Líquida as despesas "com inativos e pensionistas, ainda que pagas por intermédio de unidade gestora única ou fundo previsto no artigo 249 da Constituição Federal, quanto à parcela custeada por recursos provenientes" (art. 19, §1º, VI (BRASIL, 2021)). Essas duas alterações ilustram um quadro mais abrangente de reviravolta no regime jurídico da responsabilidade fiscal claramente já orientado para os momentos que seguirão na continuidade do desfecho da pandemia.

\section{CONSIDERAÇÕES FINAIS}

No início do ano de 2021, quando concluído o presente texto, ainda se apresentava imprevisível o real impacto da crise sanitária, gerada pela pandemia (covid-19), para as contas públicas, sendo, certamente, um dos maiores desafios da história.

Nos estados brasileiros, as finanças foram abaladas pela queda de arrecadação com o ICMS, por exemplo, bastante ligada ao ritmo da economia. É certo que, nas últimas décadas, aprofundou-se o desequilíbrio fiscal/orçamentário do Estado, devido ao aumento das demandas sociais e à crise econômica mundial, implicando acréscimos ainda maiores das

4 Contudo, ainda está pendente, no Supremo Tribunal Federal, ação de controle concentrada, que pretende atribuir interpretação, conforme a Constituição, aos arts. 18 e 19 para que as despesas com pensionistas e inativos sejam incluídas nos limites de despesas com pessoal (ADC 69). Ao que tudo indica, porém, a alteração legislativa superveniente tornou prejudicada a ação constitucional em tela (BRASIL. Supremo Tribunal Federal. Ação Declaratória de Constitucionalidade 69. Relator: ministro Alexandre de Moraes. Data: 26/02/2020. Disponível em: https://portal.stf.jus.br/processos/detalhe.asp?incidente=5862852. Acesso em: 24 mar. 2021). 
despesas públicas. Isso leva a um déficit ainda maior, na medida em que tensões sociais sugerem menor incidência tributária, sonegação fiscal, projetando menor arrecadação fiscal.

Com uma curva ascendente de demandas e de recursos limitados, chega-se ao descontrole dos gastos públicos e à escalada da dívida do Estado brasileiro, de modo geral, e, em particular, do estado do Rio Grande do Sul, como foi possível identificar, ainda que em exame preliminar, das contas pretéritas (2015 a 2017). No caso específico do estado gaúcho, também foi possível identificar grave divergência na antiga metodologia de cálculo em torno dos gastos com pessoal, fato que ocasionou o reconhecido cumprimento da Lei de Responsabilidade Fiscal no âmbito local, e a sua negação para a Secretaria do Tesouro Nacional.

Mesmo com as mudanças promovidas pela Lei Complementar $\mathrm{n}^{\circ}$ 178/2021 (BRASIL, 2021), chama a atenção o aumento, ano após ano, do percentual de inativos em relação aos servidores ativos nos gastos com pessoal, sendo que hoje representam a maioria da folha de pagamento dos servidores públicos estaduais, muito devido à incapacidade financeira de o Estado recompor seus quadros. De outro giro, há constante diminuição de receitas, devido ao período pós-crise mundial, estagnação da economia e consequente anomia fiscal.

Em arremate, apesar de a Lei Complementar no 101/2000 (BRASIL, 2000) ter inovado na questão da transparência, buscando o equilíbrio orçamentário, fiscalizando a despesa e evitando o endividamento público, a previsão de gatilhos de segurança com limites fixos calculados sobre a Receita Corrente Líquida, sem revisão periódica de acordo com a dinâmica econômica e financeira, confirmou o descompasso da Lei de Responsabilidade Fiscal com as situações financeiras de crise, especialmente no estado do Rio Grande do Sul e no contexto da covid-19.

Na prática, esse desacordo legislativo ocasionou, no âmbito do Tri- 
bunal de Contas do Estado do Rio Grande do Sul, a flexibilização de interpretações contábeis (v. g., a exclusão do imposto retido, pensões etc.), conscientes de que não se pode atribuir apenas à gestão estatal a responsabilidade pelo desequilíbrio entre receitas e despesas.

$\mathrm{O}$ advento da crise sanitária desnudou de uma vez por todas as fragilidades da Lei de Responsabilidade Fiscal, que acabou apressadamente alterada em pontos decisivos do controle fiscal, na tentativa de manter algum grau de coerência entre o dever de responsabilidade pelas contas e a imposição inevitável dos fatos sociais.

Em definitivo, as mudanças legislativas mais recentes apresentam-se como capazes e necessárias para restabelecer o fiel cumprimento da responsabilidade fiscal, pois, sem elas, o anacronismo da redação originária da Lei de Responsabilidade Fiscal e os momentos de crise financeira seriam ainda maiores. Além disso, permanece de suma importância a atuação dos Tribunais de Contas em zelar pela eficiência do gasto público e pelo atendimento satisfatório das demandas da sociedade.

\section{REFERÊNCIAS}

ABRAHAM, M. Coronavírus e a Lei de Responsabilidade Fiscal. GENJurídico.com.br. 23 mar. 2020. Disponível em: http://genjuridico.com.br/2020/03/23/ coronavirus-lei-de-responsabilidade-fiscal/. Acesso em: 2 jan. 2021.

BEZERRA, D. M.; BEZERRA, W.; SILVA, A. C. B. A Lei de Responsabilidade Fiscal e as exigências relativas a gastos com pessoal: uma análise do cumprimento da norma, no ano de 2009, pelos gestores municipais de PE, segundo os dados contidos no relatório de gestão fiscal. In: CONGRESSO USP DE INICIAÇÃO CIENTÍFICA EM CONTABILIDADE, 8., 2011, São Paulo. Anais [...]. São Paulo: FIPECAFI, 2011. p. 1-17. Disponível em: https://congressousp.fipecafi.org/anais/artigos112011/343. pdf. Acesso em: 2 jan. 2021. 
BRASIL. [Constituição (1988)]. Constituição da República Federativa do Brasil. Brasília, DF: Presidência da República. Disponível em: http:// www.planalto.gov.br/ccivil_03/constituicao/constituicao.htm. Acesso em: 27 dez. 2020.

BRASIL. Lei Complementar $n^{\mathbf{0}}$ 101, de 4 de maio de 2000. Estabelece normas de finanças públicas voltadas para a responsabilidade na gestão fiscal e dá outras providências. Disponível em: http://www.planalto.gov. br/ccivil_03/leis/lcp/lcp101.htm. Acesso em: 20 dez. 2020.

BRASIL. Supremo Tribunal Federal. Medida Cautelar na Ação Direta de Inconstitucionalidade 4.190 Rio de Janeiro. Relator: ministro Celso de Mello. Data: 10/03/2010. Disponível em: http://redir.stf.jus.br/paginadorpub/paginador.jsp?docTP=AC\&docID=612217. Acesso em: $20 \mathrm{dez}$. 2020.

BRASIL. Supremo Tribunal Federal. Recurso Extraordinário 848.826 Distrito Federal. Relator: ministro Roberto Barroso. Data: 10/08/2016. Disponível em: http://redir.stf.jus.br/paginadorpub/paginador.jsp?doc$\mathrm{TP}=\mathrm{TP} \&$ docID=13432838. Acesso em: 10 dez. 2020.

BRASIL. Lei Complementar $n^{\circ}$ 159, de 19 de maio de 2017. Institui o Regime de Recuperação Fiscal dos Estados e do Distrito Federal e altera as Leis Complementares $n^{\circ} 101$, de 4 de maio de 2000, e $n^{\circ} 156$, de 28 de dezembro de 2016. Disponível em: http://www.planalto.gov.br/ccivil_03/ leis/lcp/Lcp159.htm. Acesso em: 20 dez. 2020.

BRASIL. Supremo Tribunal Federal. Ação Declaratória de Constitucionalidade 69. Relator: ministro Alexandre de Moraes. Data: 26/02/2020a. Disponível em: https://portal.stf.jus.br/processos/detalhe.asp?incidente $=5862852$. Acesso em: 24 mar. 2021. 
BRASIL. Decreto Legislativo $\mathbf{n}^{\mathbf{0}}$ 6, de 20 de março de 2020. Reconhece, para os fins do art. 65 da Lei Complementar $n^{\circ} 101$, de 4 de maio de 2000, a ocorrência do estado de calamidade pública, nos termos da solicitação do Presidente da República encaminhada por meio da Mensagem n ${ }^{\circ}$ 93, de 18 de março de 2020. Disponível em: http://www.planalto.gov.br/ccivil_03/portaria/DLG6-2020.htm. Acesso em: 20 dez. 2020.

BRASIL. Lei $\mathbf{n}^{\mathbf{0}} \mathbf{1 3 . 9 8 2}$, de 2 de abril de 2020. Altera a Lei $\mathrm{n}^{\circ}$ 8.742, de 7 de dezembro de 1993, para dispor sobre parâmetros adicionais de caracterização da situação de vulnerabilidade social para fins de elegibilidade ao benefício de prestação continuada (BPC), e estabelece medidas excepcionais de proteção social a serem adotadas durante o período de enfrentamento da emergência de saúde pública de importância internacional decorrente do coronavírus (Covid-19) responsável pelo surto de 2019, a que se refere a Lei $\mathrm{n}^{\mathrm{o}} 13.979$, de 6 de fevereiro de 2020. Disponível em: http://www.planalto.gov.br/ccivil_03/_ato2019-2022/2020/1ei/113982. htm. Acesso em: 20 dez. 2020.

BRASIL. Lei $\mathbf{n}^{\mathbf{0}} \mathbf{1 3 . 9 8 3}$, de 3 de abril de 2020. Altera a Lei $\mathrm{n}^{\circ} 13.898$, de 11 de novembro de 2019, que dispõe sobre as diretrizes para a elaboração e a execução da Lei Orçamentária de 2020. Disponível em: http://www. planalto.gov.br/ccivil_03/_Ato2019-2022/2020/Lei/L13983.htm. Acesso em: 20 dez. 2020.

BRASIL. Emenda Constitucional $\mathbf{n}^{\mathbf{0}}$ 106, de 7 de maio de 2020. Institui regime extraordinário fiscal, financeiro e de contratações para enfrentamento de calamidade pública nacional decorrente de pandemia. Disponível em: http://www.planalto.gov.br/ccivil_03/constituicao/emendas/emc/ emc 106.htm\#: :text=1\%C2\%BA\%20Durante \%20a\%20vig\%C3\%AAncia $\% 20$ de, atender $\% 20 \%$ C3\%A 0 s\%20necessidades $\% 20$ dele $\% 20$ decorrentes\%2C. Acesso em: 20 dez. 2020. 
BRASIL. Lei no 13.999, de 18 de maio de 2020. Institui o Programa Nacional de Apoio às Microempresas e Empresas de Pequeno Porte (Pronampe), para o desenvolvimento e o fortalecimento dos pequenos negócios; e altera as Leis $\mathrm{n}^{\mathrm{o}} \mathrm{s} 13.636$, de 20 de março de 2018, 10.735, de 11 de setembro de 2003, e 9.790, de 23 de março de 1999. Disponível em: http://www. in.gov.br/en/web/dou/-/lei-n-13.999-de-18-de-maio-de-2020-257394467. Acesso em: 20 dez. 2020.

BRASIL. Lei Complementar ${ }^{0} \mathbf{1 7 3}$, de 27 de maio de 2020. Estabelece o Programa Federativo de Enfrentamento ao Coronavírus SARS-CoV-2 (Covid-19), altera a Lei Complementar $\mathrm{n}^{\circ} 101$, de 4 de maio de 2000, e dá outras providências. Disponível em: http://www.planalto.gov.br/ccivil_03/leis/lcp/Lcp173.htm. Acesso em: 20 dez. 2020.

BRASIL. Decreto $\mathbf{n}^{0} \mathbf{1 0 . 5 9 3}$, de 24 de dezembro de 2020. Dispõe sobre a organização e o funcionamento do Sistema Nacional de Proteção e Defesa Civil e do Conselho Nacional de Proteção e Defesa Civil e sobre o Plano Nacional de Proteção e Defesa Civil e o Sistema Nacional de Informações sobre Desastres. Disponível em: http://www.planalto.gov.br/ ccivil_03/_Ato2019-2022/2020/Decreto/D10593.htm\#art44. Acesso em: 24 mar. 2021.

BRASIL. Supremo Tribunal Federal. Ação Direta de Inconstitucionalidade 2.238 Distrito Federal. Relator: ministro Alexandre de Moraes. Data: 24/06/2020. Disponível em: http://redir.stf.jus.br/paginadorpub/paginador.jsp?docTP=TP\&docID=753826907. Acesso em: 2 out. 2020.

BRASIL. Secretaria do Tesouro Nacional. Nota Técnica SEI $\mathbf{n}^{0}$ 12774/2020/ME. Contabilização de Recursos Destinados ao Enfrentamento da Emergência de Saúde Pública de Importância Internacional Decorrente do Coronavírus (COVID-19). 07/04/2020. Disponível: 
http://www.igam.com.br/upload/intranet/downloads/nota-tecnica-sei-n12774-2020-mepdf.pdf. Acesso em: 20 jan. 2021.

BRASIL. Lei Complementar $n^{\mathbf{0}}$ 178, de 13 de janeiro de 2021. Estabelece o Programa de Acompanhamento e Transparência Fiscal e o Plano de Promoção do Equilíbrio Fiscal; altera a Lei Complementar $n^{\circ} 101$, de 4 de maio de 2000, a Lei Complementar $n^{\circ}$ 156, de 28 de dezembro de 2016, a Lei Complementar $n^{\circ} 159$, de 19 de maio de 2017, a Lei Complementar $n^{\circ} 173$, de 27 de maio de 2020, a Lei $n^{\circ} 9.496$, de 11 de setembro de 1997, a Lei $\mathrm{n}^{\circ} 12.348$, de 15 de dezembro de 2010, a Lei $\mathrm{n}^{\circ} 12.649$, de 17 de maio de 2012, e a Medida Provisória $n^{\circ} 2.185-35$, de 24 de agosto de 2001; e dá outras providências. Disponível em: http://www.planalto.gov. br/ccivil_03/leis/lcp/Lcp178.htm. Acesso em: 24 mar. 2021.

CARRA, F. Os níveis de endividamento do Poder Executivo do estado do Rio Grande do Sul nos períodos de 2003 a 2014 frente à Lei de Responsabilidade Fiscal. 2015. 68 f. Trabalho de Conclusão de Curso (Bacharelado em Ciências Contábeis) - Universidade de Caxias do Sul, Caxias do Sul, 2015. Disponível em: https://repositorio.ucs.br/xmlui/ bitstream/handle/11338/1738/TCC\%20Franciele\%20Carra.pdf?sequence $=1 \&$ isAllowed $=y$. Acesso em: 20 dez. 2020.

DOIA, A. R. L. A importância da lei de responsabilidade fiscal para a administração pública. Revista Científica Multidisciplinar Núcleo do Conhecimento, São Paulo, ano 1, v. 7, p. 24-36, ago. 2016.

FALCÃO, H. P. A Lei de Responsabilidade Fiscal: pessoal e dívida do estado do Rio Grande do Sul. 2013. 61 fls. Trabalho de Conclusão de Curso (Bacharelado em Ciências Econômicas) - Universidade Federal do Rio Grande do Sul, Porto Alegre, 2013. Disponível em: https://www.lume.ufrgs.br/handle/10183/79238. Acesso em: 20 dez. 2020. 
FREITAS, J. O controle dos atos administrativos e os princípios fundamentais. 4. ed. São Paulo: Malheiros, 2009.

GURGEL, C. S. Breves anotações sobre a Lei Federal no 13.982/2020, que criou o auxílio emergencial em tempo de Covid-19. Revista Jus Navigandi, Teresina, ano 25, n. 6123, 6 abr. 2020. Disponível em: http://jus. com.br/artigos/80884/breves-anotacoes-sobre-a-lei-n-13-982-2020-que-criou-0-auxilio-emergencial-em-tempo-de-covid-19. Acesso em: 2 dez. 2020.

LACERDA, C. M. V. Os impactos da pandemia de covid-19 nas ações de improbidade administrativa à luz das alterações à Lei de Introdução das Normas de Direito Brasileiro. Migalhas. 3 abr. 2020. Disponível em: https://www.migalhas.com.br/depeso/323740/os-impactos-da-pandemia-de-covid-19-nas-acoes-de-improbidade-administrativa-a-luz-das-alteracoes-da-lei-de-introducao-as-normas-do-direito-brasileiro. Acesso em: 2 nov. 2020.

LIMA, L. H.; OLIVEIRA, W. de; CAMARGO, J. B. (coord.). Contas governamentais e responsabilidade fiscal: desafios para o controle externo. Belo Horizonte: Fórum, 2018.

LUQUE, C. A.; SILVA, V. M. A Lei de Responsabilidade na gestão fiscal: combatendo falhas de governo à brasileira. Revista de Economia Política, São Paulo, v. 24, n. 3, p. 404-421, jul./set. 2004. Disponível em: https:/www.scielo.br/scielo.php?script=sci_arttext\&pi$\mathrm{d}=\mathrm{S}$ 0101-31572004000300413\&lng=en\&nrm=iso. Acesso em: $10 \mathrm{dez} .2020$.

NUNES, S. P.; NUNES, R. C. O processo orçamentário na Lei de Responsabilidade Fiscal: instrumento de planejamento. 2014. Disponível em: http://www.uberaba.mg.gov.br/portal/acervo/orcamento/boletins/O_ 
Processo_orcamentario_na_LRF_instrumento_de_planejamento.pdf. Acesso em: 10 out. 2020.

PONTES, E. Crise fiscal, Lei de Responsabilidade Fiscal e os Tribunais de Contas. TCE-CE, 8 fev. 2019. Disponível em: https://www.tce.ce.gov.br/ comunicacao/artigos/3465-crise-fiscal-brasileira-em-busca-de-um-diagnostico-correto-ou-para-evitar-bodes-expiatorios. Acesso em: 10 out. 2020 .

RIO GRANDE DO SUL. Tribunal de Contas. Prestando Contas: sumário do parecer prévio sobre as contas do governador do estado. Exercício 2015. Porto Alegre: TCE/RS, 2016. Disponível em: http://www1.tce.rs. gov.br/portal/page/portal/tcers/consultas/contas_estaduais/contas_governador/pp_simplificado_2015.pdf. Acesso em: 10 nov. 2020.

RIO GRANDE DO SUL. Tribunal de Contas. Prestando Contas: sumário do parecer prévio sobre as contas do governador do estado. Exercício 2016. Porto Alegre: TCE/RS, 2017a. Disponível em: http://www1.tce.rs. gov.br/portal/page/portal/tcers/consultas/contas_estaduais/contas_governador/pp_simplificado_2016.pdf. Acesso em: 20 dez. 2020.

RIO GRANDE DO SUL. Tribunal de Contas. Informação no 21/2017 SAIPAG. Porto Alegre: TCE/RS, $2017 \mathrm{~b}$.

RIO GRANDE DO SUL. Tribunal de Contas. Prestando Contas: sumário do parecer prévio sobre as contas do governador do estado. Exercício 2017. Porto Alegre: TCE/RS, 2018. Disponível em: http://www1.tce.rs. gov.br/portal/page/portal/tcers/consultas/contas_estaduais/contas_governador/pp_simplificado_2017.pdf. Acesso em: 20 dez. 2020. 
SANTANNA, G. S. Administração pública em juízo. Porto Alegre: Verbo Jurídico, 2013.

SANTANNA, G. S. Direito administrativo: série objetiva. 4. ed. Porto Alegre: Verbo Jurídico, 2015.

SILVA, J. A. da. Curso de direito constitucional positivo. 24. ed. São Paulo: Malheiros, 2005. 